\title{
Atributos Corporativos, Qualidade da Governança Corporativa e Valor das Companhias Abertas no Brasil
}

\author{
Alexandre Di Miceli da Silveira* \\ Lucas Ayres B. de C. Barros** \\ Rubens Famá***
}

\begin{abstract}
Resumo
Este artigo investiga a influência da qualidade da governança corporativa sobre o valor de mercado de 154 companhias abertas brasileiras em 2002. Como forma de avaliar a qualidade da governança das empresas, utilizou-se um índice amplo de práticas de governança. A investigação empírica foi conduzida por meio de diferentes abordagens econométricas, em ordem crescente de complexidade, incluindo regressões múltiplas por mínimos quadrados ordinário, variáveis instrumentais e sistemas de equações simultâneas. Os resultados obtidos em todas as abordagens mostram uma influência positiva e significante da qualidade da governança corporativa sobre o valor de mercado das empresas. O estudo obtém evidências de endogeneidade da variável de governança corporativa, para a qual são propostos diferentes instrumentos. Por fim, os resultados obtidos com os sistemas de equações simultâneas sugerem uma relação de causalidade de mão-dupla entre a qualidade da governança corporativa e o valor das empresas.
\end{abstract}

Palavras-chave: governança corporativa; índice de Governança, atributos corporativos, valor de mercado.

Códigos JEL: G32; G34.

\begin{abstract}
This paper investigates the influence of corporate governance quality on the market value of 154 Brazilian listed companies in 2002. As a proxy for corporate governance quality, a broad governance index was built. The empirical investigation employed different econometric approaches with increasing level of complexity, including multiple regressions by ordinary least squares, instrumental variables estimators and simultaneous equations systems. Results obtained with all econometric approaches show a positive and significant influence of corporate governance quality on firms' market values. The paper also finds evidence of endogeneity of the corporate governance variable, for which different instruments are proposed. Moreover, results obtained with the simultaneous equations approach suggest that there might be a two-way causality link between corporate governance quality and firm valuation.
\end{abstract}

Keywords: corporate governance; governance index; corporate attributes; firm value.

\footnotetext{
Submetido em Fevereiro de 2006. Revisado em Maio de 2006.

*FEA/USP. E-mail: alexfea@usp.br

**Universidade Presbiteriana Mackenzie. E-mail: lucasayres2002@yahoo.com.br

***FEA/USP. E-mail: rfama@usp.br
} 


\section{Introdução}

Toda a discussão sobre governança corporativa parte da hipótese de que os mecanismos de governança influenciam o desempenho das empresas. Em essência, a questão básica nas pesquisas é saber se o valor de mercado das companhias é determinado por mecanismos internos ou externos de governança. Entretanto, ainda não existe um arcabouço teórico ou evidências empíricas conclusivas sobre como (e se) os mecanismos de governança influenciam o desempenho corporativo e sobre como esses mecanismos se relacionam, se de forma complementar ou substituta.

A maior parte dos estudos analisa individualmente a possível influência de mecanismos específicos de governança (como concentração da estrutura de propriedade, estrutura do conselho de administração, estrutura de capital, presença de um mercado de aquisições hostis, política de remuneração, etc.) sobre variáveis de desempenho corporativo (como indicadores contábeis de rentabilidade e métricas de valor de mercado). Nessas pesquisas, os mecanismos de governança atuam como variáveis explicativas e as variáveis de desempenho como variáveis dependentes.

Assume-se, desta forma, na grande maioria dos estudos, que os mecanismos de governança são variáveis exógenas, portanto não determinadas por outros mecanismos de governança ou demais características da empresa. É possível, entretanto, que alguns mecanismos de governança, ou a própria qualidade da governança corporativa, sejam, de fato, variáveis endógenas, isto é, variáveis influenciadas por outros mecanismos de governança ou por outros atributos das empresas. Caso isso seja verdade, os diversos estudos realizados que objetivavam capturar o impacto isolado de mecanismos de governança sobre o desempenho podem ter apresentado resultados enviesados e inconsistentes, por utilizarem a premissa de que os mecanismos de governança são exógenos na influência sobre o desempenho corporativo.

Neste contexto, o presente trabalho tem como objetivo principal investigar a influência da qualidade da governança corporativa sobre o valor das companhias abertas brasileiras por meio de diferentes abordagens econométricas em ordem crescente de complexidade, incluindo regressões múltiplas por mínimos quadrados ordinário, variáveis instrumentais e sistemas de equações simultâneas. O propósito desta estratégia é verificar a robustez da relação estimada entre governança corporativa e valor a distintas modelagens e técnicas econométricas. Isto é considerado importante pela recente literatura, já que as abordagens de regressões múltiplas por mínimos quadrados ordinário (MQO) tratam a governança corporativa como uma variável exógena, enquanto as abordagens utilizando variáveis instrumentais e sistemas de equações simultâneas tratam a governança corporativa como uma variável endógena, sendo utilizadas para mitigar os problemas de variáveis omitidas e de causalidade reversa entre governança corporativa e valor. Entre os principais estudos utilizados como base para a pesquisa, destacam-se os de Agrawal e Knoeber (1996), Barnhart e Rosenstein (1998), Cho (1998), Bhagat e Jefferis (2002), Claessens et alii (2002), Demsetz e Villalonga (2001), Klapper e Love 
(2002), Bøhren e Ødegaard (2003) e Leal e Carvalhal da Silva (2005a,b).

A principais contribuições do estudo são as seguintes: 1) A pesquisa discute a importância da obtenção de instrumentos adequados nas pesquisas sobre governança corporativa para minimizar os problemas de endogeneidade e propõe novos instrumentos passíveis de serem usados em estudos posteriores; 2) A pesquisa trata os mecanismos de governança não apenas como variáveis exógenas, mas também como variáveis endógenas, por meio da construção de um sistema de equações simultâneas no qual as variáveis de governança e desempenho se interrelacionam e os coeficientes são estimados conjuntamente. Segundo Bøhren e Ødegaard (2003, pág. 2), a abordagem de equações simultâneas é capaz de lidar com os problemas de causalidade reversa e outras fontes de endogeneidade, sendo utilizada apenas recentemente em estudos sobre o tema; 3) A pesquisa compara os resultados obtidos na relação entre governança corporativa e valor por meio de distintas abordagens econométricas em ordem crescente de complexidade, permitindo comparar se a direção e a significância dos coeficientes dependem da abordagem utilizada. Particularmente, a comparação dos resultados utilizando a abordagem de variáveis instrumentais e de equações simultâneas com os obtidos utilizando a abordagem tradicional de regressões múltiplas por MQO pode ser muito útil para discutir a validade e a consistência dos resultados das pesquisas sobre o tema.

$\mathrm{O}$ estudo parte da hipótese de que existe um relacionamento significativo, do ponto de vista estatístico, entre a qualidade da governança corporativa e o valor de mercado das empresas e que as empresas com maior qualidade de governança apresentam maior valor de mercado, ceteris paribus. O artigo está estruturado da seguinte forma: a seção 2 apresenta a fundamentação teórica da pesquisa. A seção 3 apresenta o método do estudo, incluindo a descrição das variáveis utilizadas, dos procedimentos empíricos e da amostra. A seção 4 discute os principais resultados obtidos. A seção 5 apresenta as considerações finais do trabalho.

\section{Fundamentação Teórica}

As pesquisas na busca de evidências da influência da governança corporativa sobre o valor das empresas podem ser classificadas de acordo com a abordagem econométrica empregada. Bøhren e Ødegaard (2003, pág. 8) propõem uma classificação, apresentada no quadro a seguir:

Abordagens econométricas das pesquisas sobre governança corporativa

\begin{tabular}{lcc}
\hline & \multicolumn{2}{c}{ Relação de causalidade } \\
\hline Mecanismos de governança & Sentido único & Sentido duplo \\
\hline Exógenos & 1 & 3 \\
Endógenos & 2 & 4 \\
\hline Bøhren, Ø. and Ødegaard, B., "Governance and Performance Revisi- \\
ted", ECGI working paper series in finance, n. & $28 / 2003$, September, \\
2003.
\end{tabular}

Segundo Bøhren e Ødegaard (2003), a quase totalidade dos estudos sobre governança corporativa pertence à célula 1, empregando uma abordagem eco- 
nométrica baseada em três premissas: i) os mecanismos de governança são variáveis exógenas; ii) a causalidade apresenta um sentido único da governança corporativa para o valor das empresas; e iii) as regressões são rodadas por meio de equações isoladas utilizando um ou alguns dos mecanismos de governança. Entre os mecanismos de governança mais testados contra as variáveis de desempenho, destacam-se mecanismos internos, como a concentração da propriedade, a estrutura do conselho e a forma de remuneração dos executivos, e mecanismos externos, como o mercado de controle corporativo, o nível de endividamento e a presença de investidores institucionais.

Segundo Bøhren e Ødegaard (2003), alguns estudos, como o de Himmelberg et alii (1999), se aproximam da abordagem apresentada na célula 2. Nesse estudo, os autores analisam a relação de causalidade em um sentido único, indo da estrutura de propriedade para o desempenho, de forma similar aos estudos pertencentes à célula 1. Entretanto, os autores tratam a concentração da propriedade como uma variável potencialmente endógena, analisando seus possíveis determinantes por meio de técnicas de dados em painel que levam em conta os efeitos fixos das companhias (características não observáveis das empresas invariantes ao longo do período de análise). Com relação à célula 3, Bøhren e Ødegaard (2003, pág. 9) afirmam que tais estudos são inviáveis, já que não é possível modelar uma relação de causalidade em sentido duplo sem considerar ao menos um mecanismo de governança como endógeno em relação ao desempenho. Por fim, a célula 4 corresponde às pesquisas que estimam os coeficientes dos mecanismos de governança corporativa e das variáveis de desempenho por meio de sistemas de equações simultâneas utilizando variáveis instrumentais, como os trabalhos de Agrawal e Knoeber (1996), Barnhart e Rosenstein (1998), Cho (1998) e Demsetz e Villalonga (2001).

Como existe uma razoável probabilidade de ocorrência dos problemas econométricos de causalidade reversa e endogeneidade nos estudos sobre governança corporativa, tem-se um ponto a favor da adoção da abordagem da célula 4, que lida mais diretamente com esses problemas. Entretanto, a implementação correta de tais métodos depende de a teoria oferecer restrições adequadas e embasadas conceitualmente para os sistemas de equações. Segundo Bøhren e Ødegaard (2003, pág. 9), a literatura teórica sobre governança corporativa ainda não estabeleceu como os mecanismos de governança interagem, quais variáveis são exógenas e qual é a natureza do equilíbrio entre elas para uma combinação ótima dos mecanismos de governança. Em resumo, uma questão chave ainda não resolvida, dada a ausência de uma teoria bem estabelecida sobre governança corporativa, é se os resultados utilizando a abordagem da célula 4 fornecem evidências mais confiáveis sobre a relação entre mecanismos de governança e valor do que os resultados dos estudos que utilizam a abordagem mais simples e tradicional da célula 1 .

Existe uma miríade de estudos buscando relacionar mecanismos de governança e valor das empresas. Na seqüência, são apresentados os resultados de estudos considerados mais compatíveis com as estratégias empregadas na presente pes- 
quisa. Nestes estudos são construídos índices de governança corporativa amplos que resumem em uma única medida informações relativas a diversos mecanismos e práticas de governança, como forma de obter uma aproximação mais adequada para a qualidade da governança corporativa. Resumos das principais pesquisas empíricas sobre a relação entre governança e desempenho podem ser encontrados em Leal (2004), Bhagat e Jefferis (2002) e Denis e McConnell (2003).

Black (2001) avalia a hipótese de que o comportamento das práticas de governança afeta o valor de mercado das empresas na Rússia. Como aproximação para a qualidade da governança corporativa, o autor utilizou um ranking criado pelo banco de investimento Brunswick Warburg, que atribuiu uma pontuação de 0 a 60 pontos, com índices maiores indicando maior "risco de governança corporativa". Os resultados da pesquisa indicaram uma forte relação positiva entre qualidade da governança corporativa e valor de mercado das empresas, sugerindo que o comportamento da empresa em termos de práticas de governança pode ter um efeito considerável sobre seu valor de mercado, principalmente em um país onde a proteção ao investidor é fraca. O próprio autor ressalta, entretanto, que os resultados são limitados pela pequena amostra (dezesseis empresas) e pela ausência de variáveis de controle.

Klapper e Love (2002) avaliam a diferença na qualidade da governança corporativa das empresas de quatorze países emergentes utilizando como base um índice de governança corporativa criado pelo banco Credit Lyonnnais Securities Asia (CSLA). As autoras avaliam a relação entre a qualidade da governança corporativa e o desempenho das empresas, encontrando uma alta correlação positiva entre qualidade da governança e valor de mercado das empresas. Como os resultados foram obtidos por meio do método dos mínimos quadrados para um período de um ano, as autoras alertam para o possível problema de endogeneidade na relação entre as variáveis, evitando concluir sobre qualquer relação de causalidade da qualidade da governança sobre o desempenho das empresas.

Bøhren e Ødegaard (2003) analisam a relação entre governança corporativa e desempenho na Noruega. Inicialmente, os autores realizaram regressões isoladas com diversos mecanismos de governança atuando como variáveis independentes. Os resultados da primeira parte do estudo mostraram evidências de que os mecanismos de governança são relevantes para explicar o desempenho das empresas analisadas. Na seqüência, os autores utilizaram a abordagem de equações simultâneas. Os resultados utilizando esta abordagem mostraram uma ausência de significância ou inversão de sinais nas relações entre os mecanismos de governança e as variáveis de valor. Os autores creditam a mudança de resultados principalmente à dificuldade metodológica de se utilizar um sistema de equações simultâneas, decorrente de teorias ainda subdesenvolvidas na explicação sobre como governança corporativa e desempenho interagem.

Black et alii (2006) reportam evidências de que a governança corporativa é um fator importante na predição do valor de mercado das empresas na Coréia do Sul. Os autores construíram um índice de governança amplo como aproximação da qua- 
lidade da governança das empresas. Inicialmente, os autores realizaram regressões por MQO com diversas especificações alternativas dos modelos, constatando uma forte associação positiva entre qualidade da governança e valor de mercado. Reconhecendo a possibilidade de problemas de endogeneidade, os autores realizaram em seguida estimações dos coeficientes por variáveis instrumentais utilizando os estimadores de mínimos quadrados de dois estágios (MQ2E) ${ }^{1}$ e de mínimos quadrados de três estágios (MQ3E). ${ }^{2}$ A grande dificuldade de utilização dessa abordagem reside em encontrar um instrumento adequado para a governança corporativa. Os autores argumentam que a legislação da Coréia do Sul oferece características únicas para a construção de um bom instrumento, uma vez que diversas exigências de governança se aplicam apenas a empresas com ativos de no mínimo 2 trilhões de won. Desta forma, os autores construíram um instrumento que é, por definição, uma variável exógena determinada pela lei e correlacionada com a qualidade da governança. Os resultados obtidos com os procedimentos MQ2E e MQ3E utilizando o instrumento descrito mostraram a causalidade indo das boas práticas de governança para um maior valor de mercado das companhias. Desta forma, Black et alii (2006) oferecem fortes evidências, não disponíveis até então, de que melhores práticas de governança provavelmente causam um maior preço das ações em mercados emergentes.

Durnev e Kim (2005) examinam como determinados atributos das empresas influenciam a escolha das práticas de governança e interagem com o ambiente legal onde estão inseridas. Os autores desenvolvem um modelo teórico que resulta em três predições: i) as oportunidades de crescimento, a necessidade de financiamento externo e a concentração da propriedade são os três principais atributos que levam as empresas a adotarem melhores práticas de governança; ii) as empresas com melhores práticas de governança são mais valorizadas pelo mercado; e iii) a adoção de melhores práticas de governança é mais relevante em países com fraca proteção legal aos investidores. Na seqüência, os autores realizam testes empíricos, obtendo evidências que corroboram todas as predições do modelo. Como ressalva aos resultados encontrados, deve-se destacar que os autores utilizaram como aproximações para a qualidade da governança um índice criado pelo banco Credit Lyonnnais Securities Asia (CSLA) e um índice do Standard \& Poor's $(\mathrm{S} \& \mathrm{P})$, que avaliam apenas as maiores empresas de cada país e que possuem importantes limitações. ${ }^{3}$

Leal e Carvalhal da Silva (2005b) investigam a relação entre a qualidade das práticas de governança corporativa e o valor e desempenho das companhias abertas brasileiras por meio da construção de um índice de governança amplo. Foram atribuídos pesos iguais às questões, de forma que a pontuação das empresas varia em uma escala de 0 a 15 . O índice foi construído com base em dados secundários,

\footnotetext{
${ }^{1} \mathrm{O}$ MQ2E é uma tradução livre do procedimento 2SLS (two-stage least squares).

${ }^{2} \mathrm{O}$ MQ3E é uma tradução livre do procedimento 3SLS (three-stage least squares).

${ }^{3} \mathrm{O}$ índice CSLA se baseia em diversas questões subjetivas a serem respondidas pelos analistas, enquanto o índice S\&P é restrito a questões relativas à transparência das informações.
} 
possibilitando a elaboração de índices relativos ao período de 1998 a 2002. Os testes da relação entre qualidade da governança corporativa e o desempenho foram realizados por meio de análises de dados em painel utilizando os procedimentos de efeitos comuns, efeitos fixos e efeitos aleatórios. Como resultados principais, observou-se que apenas $4 \%$ das empresas apresentaram práticas de governança consideradas "boas" e que as empresas com melhor governança corporativa apresentaram maior valor de mercado (aproximado pelo $Q$ de Tobin) e melhor rentabilidade (aproximada pelo retorno sobre os ativos - ROA).

\section{Método da Pesquisa}

\subsection{Modelo de pesquisa e discussão metodológica}

O objetivo da pesquisa é avaliar como a governança corporativa influencia o valor de mercado das empresas abertas. Com este intuito, a relação entre governança corporativa e valor foi investigada por meio de um conjunto de abordagens econométricas distintas: regressões isoladas utilizando mínimos quadrados ordinário, regressões isoladas utilizando variáveis instrumentais (estimadas por mínimos quadrados de dois estágios, MQ2E, e pelo método dos momentos generalizado, $\mathrm{MMG})^{4}$ e sistemas de equações simultâneas (estimados por MMG, por mínimos quadrados de três estágios, MQ3E, e pelo método de máxima verossimilhança com informação completa, MVIC). ${ }^{5}$ Inicialmente, a relação mais simples entre governança corporativa e valor pode ser visualizada através do seguinte modelo:

$$
V A L O R_{i}=\beta_{0}+\beta_{1} G O V_{i}+\varepsilon_{i}
$$

onde $V A L O R_{i}$ representa o valor de mercado da i-ésima empresa, $G O V_{i}$ representa a qualidade da governança corporativa da i-ésima empresa e $\varepsilon_{i}$ representa o termo de erro aleatório da i-ésima empresa. A aplicação do método MQO ao modelo acima, entretanto, deverá resultar num estimador inconsistente e enviesado para o parâmetro $\beta_{1}$, tendo em vista que diversas variáveis corporativas capturadas pelo termo de erro da regressão podem ser correlacionadas com o valor das empresas e com a qualidade da governança corporativa simultaneamente. Para lidar inicialmente com esta questão, foram computadas regressões múltiplas utilizando uma série de atributos corporativos como variáveis de controle, de acordo com o seguinte modelo:

$$
\begin{aligned}
& V_{A L O R_{i}}=\beta_{0}+\beta_{1} G O V_{i}+\beta_{2} E_{S T P R O P}+\beta_{3} E S T C A P_{i} \\
& +\beta_{4} L I Q_{i}+\beta_{5} \text { PAYOUT }_{i}+\beta_{6} \text { RENTAB } \\
& +\beta_{7} C R E C_{i} \\
& +\beta_{8} \log (R E C)_{i}+\beta_{9} T A N G_{i}+\sum_{j=1}^{17} \delta_{j} I N D_{j i}+\varepsilon_{i}
\end{aligned}
$$

${ }^{4} \mathrm{O}$ MMG é uma tradução livre do procedimento GMM (generalized method of moments).

${ }^{5} \mathrm{O}$ MVIC é uma tradução livre do procedimento FILM (full information maximum likelihood). 
onde:

ESTPROP - estrutura de propriedade; ESTCAP - estrutura de capital; $L I Q$ liquidez das ações; $P A Y O U T$ - índice de payout das ações; RENT AB - rentabilidade; $C R E C$ - oportunidades de crescimento; $\log (R E C)$ - porte da empresa (logaritmo da receita líquida); $T A N G$ - natureza das operações (tangibilidade dos ativos da empresa); $I N D$ - variáveis binárias que identificam o setor de atuação da empresa.

A equação 2 foi estimada pelo método dos mínimos quadrados ordinário (MQO). Apesar da utilização de diversas variáveis de controle, os coeficientes estimados por MQO ainda podem se mostrar enviesados e inconsistentes, conforme discutido abaixo.

Os dois problemas principais de endogeneidade nas pesquisas sobre governança corporativa remetem à possível presença de variáveis omitidas e à eventual determinação simultânea das variáveis de interesse. Com relação ao problema de variáveis omitidas, é possível que características das empresas não diretamente mensuráveis ou não controladas na regressão influenciem simultaneamente os regressores e a variável dependente. Entre estas características não perfeitamente controladas, poder-se-ia citar as perspectivas de crescimento da empresa e as oportunidades de expropriação dos minoritários disponíveis para o seu controlador. Como exemplo, a oportunidade de expropriação dos minoritários pode ser correlacionada negativamente com o valor de mercado das empresas e positivamente com a qualidade da governança corporativa (como forma do controlador sinalizar ao mercado que não tem intenção de prejudicar os demais investidores usufruindo de certos benefícios privados do controle). Se tal hipótese for verdadeira, esta variável (caso não seja observável) poderia induzir um relacionamento aparentemente nulo ou negativo entre governança corporativa e valor das empresas. Neste caso, a eventual fraqueza dos resultados por obtidos por MQO seria devida ao problema de variáveis omitidas.

O problema de determinação simultânea ocorre se há uma relação de causalidade de mão-dupla estrutural entre a qualidade da governança e o valor de mercado das empresas. Neste caso, a relação não aconteceria apenas no sentido da adoção de melhores práticas de governança para o valor de mercado da empresa, mas também no sentido inverso, com as empresas mais bem avaliadas pelo mercado adotando melhores práticas de governança. Em situações como esta, as variáveis de interesse seriam determinadas simultaneamente e a estimação por MQO geralmente produziria estimadores enviesados e inconsistentes.

Como há forte suspeita na literatura pertinente de que os mecanismos de governança são variáveis endógenas, a relação entre qualidade da governança e valor deve receber um tratamento mais adequado do que o procedimento por MQO. Uma solução para os problemas de endogeneidade seria a utilização de variáveis instrumentais, as quais deveriam apresentar duas propriedades essenciais: possuir uma correlação forte com a qualidade da governança corporativa e uma correlação nula com o termo de erro da equação original. Em outras palavras, os instrumentos 
deveriam afetar a medida de valor apenas por meio da governança corporativa e das outras variáveis observáveis e controladas. ${ }^{6}$

Um instrumento ideal poderia originar-se de um fenômeno intrinsecamente exógeno. Como exemplo, ter-se-ia um bom instrumento caso o governo sorteasse aleatoriamente algumas empresas e as obrigasse a seguir determinadas práticas de governança. Na ausência de fenômenos puramente exógenos, as recentes pesquisas têm utilizado alguns instrumentos mais ou menos questionáveis. Durnev e Kim (2005), por exemplo, utilizam o setor de atuação das empresas como instrumento para o seu valor de mercado. Já no estudo de Black et alii (2006), descrito na seção 2, os autores aproveitam uma peculiaridade legal do mercado sul coreano para utilizar um instrumento mais convincentemente exógeno.

No presente artigo, após a estimação por MQO, a relação entre governança corporativa e valor foi estimada pela abordagem de variáveis instrumentais utilizando o procedimento MQ2E. Foram selecionados cinco instrumentos para a variável de governança corporativa: 1) emissão de ADRs (American Depositary Receipts) Nível 1; 2) emissão de ADRs Nível 2 ou Nível 3; 3) Adesão aos níveis de governança corporativa da Bovespa; 4) variável binária de tamanho da empresa; 5) Identidade do acionista controlador. A hipótese que justifica a escolha dos instrumentos é que essas variáveis somente afetam o valor das empresas por meio da qualidade da governança corporativa e das correlações parciais com as outras variáveis de controle, de acordo com os seguintes argumentos:

- A emissão de ADRs e a adesão aos níveis de governança da Bovespa impõem às empresas melhores práticas de governança. Desta forma, assumese que essas variáveis devem ser correlacionadas com a qualidade da governança corporativa e que sua influência sobre o valor das empresas ocorra apenas por meio do aprimoramento percebido na qualidade da governança e das correlações com outras variáveis controladas no modelo, como a liquidez das ações;

- A variável binária de tamanho da empresa (DT AM) separa as companhias em dois grupos ("grandes" e "pequenas") com base na mediana do ativo total da amostra. Estudos anteriores, como o de Silveira et alii (2004a), constataram uma forte relação positiva entre tamanho das empresas e qualidade da governança no Brasil, ${ }^{7}$ possivelmente motivada pela maior necessidade de captação externa das empresas de maior porte e por sua maior disponibilidade de recursos para arcar com os custos associados à implementação e manutenção de práticas de governança. Por outro lado, um argumento a

\footnotetext{
${ }^{6}$ Enquanto a correlação da governança corporativa com a variável instrumental é observável, a hipótese de correlação nula do instrumento com o termo de erro não é diretamente observável, devendo se apoiar em suposições teóricas.

${ }^{7}$ Os dados do presente estudo também mostraram uma forte correlação $(0,60$, significante a $1 \%)$ entre tamanho das empresas (medido pelo logaritmo dos ativos) e a qualidade da governança corporativa (IGOV).
} 
favor da exogeneidade de DT AM é que as empresas em geral não escolhem participar de um ou de outro grupo. Assim, utilizou-se esta variável como instrumento, assumindo que sua influência sobre o valor ocorre apenas através de seu efeito sobre a qualidade da governança corporativa, depois de isoladas as características observadas das empresas. Como forma de filtrar o eventual efeito direto do porte das empresas sobre seu valor de mercado, utilizou-se adicionalmente nas regressões, como controle, uma variável contínua calculada como o logaritmo da receita operacional líquida $(\log (R E C))$, de forma similar ao procedimento empregado por Black et alii (2006);

- As variáveis binárias de identidade do acionista controlador (IDENT) podem ser consideradas aproximadamente exógenas, já que não existem evidências de que os controladores são escolhidos endogenamente a partir de características corporativas. Por outro lado, verificou-se uma correlação significativa entre IDENT e o índice de governança utilizado. Desta forma, utilizou-se alternativamente esta variável como instrumento em algumas regressões.

Além da abordagem de variáveis instrumentais com equação única, o presente estudo estimou a relação entre governança corporativa e valor por meio de sistemas de equações. Essa abordagem possui potencial para solucionar o problema de determinação simultânea, além do problema de variáveis omitidas. É importante destacar que o procedimento MQ3E, o mais empregado na estimação de sistemas deste tipo, também utiliza os instrumentos mencionados acima, mas leva em conta, adicionalmente, a eventual correlação entre os termos de erro das equações do sistema. A vantagem deste método é sua maior eficiência assintótica em comparação com a abordagem de variáveis instrumentais com equação única, supondo que o sistema esteja corretamente especificado. Todavia, em amostras pequenas os procedimentos de equações simultâneas nem sempre são mais eficientes.

Por fim, além das variáveis de governança corporativa e valor serem potencialmente endógenas, também existe a possibilidade de outras variáveis de controle não serem exógenas. Neste caso, seria necessário definir instrumentos para todos os regressores endógenos, já que os mesmos poderiam afetar os coeficientes das variáveis de interesse. Estudos prévios, como os oferecidos por Agrawal e Knoeber (1996), Barnhart e Rosenstein (1998) e Bhagat e Jefferis (2002) sugerem a necessidade de se estruturar um sistema modelando não apenas a relação entre governança corporativa e valor, mas também entre outras variáveis corporativas possivelmente endógenas. Este sistema completo, o qual poderíamos denominar "equações estruturais de finanças corporativas", pode ser representado com a seguinte estrutura geral, servindo como padrão de referência para estudos posteriores: 


$$
\begin{gathered}
\text { VALOR }=f\left(G O V, E S T P R O P, E S T C A P, L I Q, P A Y O U T, Z_{1}, \varepsilon_{1}\right) \\
G O V=f\left(V A L O R, E S T P R O P, L I Q, P A Y O U T, Z_{2}, \varepsilon_{2}\right) \\
E S T P R O P=f\left(G O V, V A L O R, L I Q, P A Y O U T, Z_{3}, \varepsilon_{3}\right) \\
E S T C A P=f\left(G O V, V A L O R, E S T P R O P, P A Y O U T, Z_{4}, \varepsilon_{4}\right) \\
L I Q=f\left(G O V, V A L O R, E S T P R O P, Z_{5}, \varepsilon_{5}\right) \\
P A Y O U T=f\left(G O V, V A L O R, E S T P R O P, E S T C A P, Z_{6}, \varepsilon_{6}\right)
\end{gathered}
$$

onde os $Z_{j}, j=1, \ldots, 6$ são os vetores contendo os instrumentos que influenciam as variáveis dependentes e os $\varepsilon_{j}, j=1, \ldots, 6$ são os termos de erro associados cada equação. O presente estudo enfocará apenas as duas primeiras equações, devido às seguintes razões: i) os dados disponíveis não seriam suficientes para estimar a grande quantidade de parâmetros do sistema acima; ii) não é fácil encontrar instrumentos adequados (justificáveis) para todas as variáveis potencialmente endógenas; e iii) recentes estudos, como o de Silveira et alii (2004b), mostram que variáveis como a concentração da estrutura de propriedade (terceira equação do sistema) não parecem ser determinadas de forma endógena no Brasil. Visando a mitigar o problema decorrente da possível determinação simultânea de certas variáveis de controle, a pesquisa utilizou todas elas defasadas em um instante de tempo (calculadas para o ano anterior), reduzindo a preocupação quanto à correlação destes regressores com os erros contemporâneos.

\subsection{Definição teórica e operacional das variáveis}

\section{Qualidade da governança corporativa}

A pesquisa utiliza como aproximação para a qualidade da governança corporativa o índice proposto por Silveira et alii (2004a). O índice, denominado IGOV, foi calculado a partir de um conjunto de 20 perguntas binárias e objetivas. $\mathrm{O}$ índice foi construído de forma a levar em conta quatro dimensões consideradas importantes pela literatura para avaliação das práticas de governança corporativa: acesso às informações; conteúdo das informações; estrutura do conselho de administração; e estrutura de propriedade e controle. As perguntas do índice são descritas no Apêndice. 


\section{Valor de mercado das empresas}

Existem várias definições operacionais possíveis para este conceito. No estudo serão utilizadas duas variáveis:

- $Q$ de Tobin $(Q)$ : estimado pela aproximação proposta por Chung e Pruitt (1994, pág. 72) e definido operacionalmente como:

$$
Q \text { de Tobin }=\frac{V M A O+V M A P+D I V T}{A T}
$$

- Múltiplo valor de mercado sobre patrimônio líquido ( $P B V$ - price-to-book value): este indicador será uma alternativa ao Q de Tobin, sendo calculado como:

$$
P B V=\frac{V M A O+V M A P}{P L}
$$

onde:

$V M A O$ - valor de mercado das ações ordinárias; $V M A P$ - valor de mercado das ações preferenciais; $D I V T$ - valor contábil da dívida, definido como passivo circulante mais exigível a longo prazo mais estoques menos o ativo circulante; $A T$ - ativo total da companhia; $P L$ - patrimônio líquido da companhia. Os dados contábeis são referentes ao respectivo exercício e a cotação das ações corresponde ao preço médio do último dia de negociação dos quatro trimestres de 2002. Em caso de ausência de informação, a cotação da ação ordinária foi aproximada pela cotação da ação preferencial. ${ }^{8}$

\section{Variáveis de controle}

- Estrutura de propriedade: variável $C O N$, definida como o percentual de ações ordinárias em posse do(s) acionista(s) controlador(es) ${ }^{9}$

- Estrutura de capital: variável $D I V P L$, definida como a dívida financeira total sobre o patrimônio líquido da empresa.

- Liquidez: variável $L I Q$, calculada pelo sistema de informações Economática ${ }^{\circledR}$ com base no volume de negócios com a ação durante o ano.

- Índice de payout: variável PAYOUT, definida como dividendos pagos por ação sobre o lucro líquido por ação ao final do exercício.

${ }^{8}$ Todos os dados contábeis e financeiros foram deflacionados pelo IPCA, com data base em $31 / 12 / 2002$

${ }^{9}$ Os dados foram coletados por meio do sistema Divext da CVM, entendendo-se como acionista controlador aquele identificado pela própria empresa no seu Informativo Anual (IAN). Para identificar corretamente o percentual de votos em posse dos controladores, analisou-se também as estruturas indiretas de propriedade, identificando-se os proprietários em comum entre vários acionistas e não somente o controle direto. 
- Rentabilidade das empresas: variável $L A J I R D A$, definida como o lucro antes dos juros, imposto de renda, depreciação e amortização sobre o ativo total:

- Oportunidades futuras de crescimento: variável $C R E C$, definida como o crescimento percentual acumulado da receita operacional dos três últimos anos.

- Porte da empresa: variável $\log (R E C)$, definida como o logaritmo da receita operacional líquida da empresa. Também utilizou-se a variável binária $D T A M$, a qual assume valor igual a 1 (um) se a empresa tiver um ativo total superior à mediana do ativo total da amostra do estudo ${ }^{10} \mathrm{e}$ assume valor igual a 0 (zero) caso contrário.

- Natureza da operação: variável $T A N G$, definida como o ativo imobilizado bruto sobre a receita operacional líquida. É uma aproximação para o nível de tangibilidade das operações da empresa.

- Setor de Atuação: conjunto de variáveis binárias ( IND) para representar os diferentes setores nos modelos. As variáveis atribuem valor 1 para as empresas pertencentes a um setor específico e 0 para as empresas pertencentes aos demais setores. Foi adotado o critério de classificação do banco de dados Economática ${ }^{\circledR}$, que fornece a relação das empresas e dos seus respectivos setores. É uma classificação ampla, dividindo as empresas em 18 categorias.

- Identidade do acionista controlador: conjunto de variáveis binárias (IDENT) para representar os diferentes tipos de acionistas controladores: (i) propriedade privada estrangeira: controle em posse de multinacional ou grupo de investidores de origem estrangeira $\left(I D E N T_{1}\right)$; (ii) propriedade privada nacional: controle de um grupo de investidores de origem nacional, não sendo os investidores da família fundadora da empresa $\left(I D E N T_{2}\right)$; (iii) propriedade familiar: controle em posse de uma família ou um único investidor, incluindo-se neste caso os controles exercidos por fundações ou por holdings que representam os fundadores ou herdeiros da empresa $\left(I D E N T_{3}\right)$; (iv) propriedade por bancos e outras instituições financeiras: controle em posse de um banco e/ou instituição financeira $\left(I D E N T_{4}\right)$; (v) propriedade de fundos de pensão: controle exercido por fundos de pensão (IDENT $T_{5}$ ); (vi) propriedade estatal: controle exercido pela União, Estados ou Municípios $\left(I D E N T_{6}\right)$.

- Emissão de ADRs: variável $A D R 1$ ou variável $A D R 23$. São variáveis binárias que assumem valor igual a 1 (um) se a empresa negocia ADRs na

\footnotetext{
${ }^{10}$ A mediana do ativo total das 154 empresas componentes da amostra foi de aproximadamente $\mathrm{R} \$$ 1,4 bilhão. Desta forma, as empresas com ativo total superior a esse valor receberam valor igual a 1 (um) na dummy de tamanho, enquanto as demais receberam valor igual a 0 (zero).
} 
bolsa de Nova York ou na NASDAQ ( $A D R 1$ caso a empresa negocie ADRs nível 1 e $A D R 23$ caso a empresa negocie ADRs nível 2 ou 3) e assume valor igual 0 (zero) caso contrário. ${ }^{11}$

- Adesão aos Níveis de GC da Bovespa: variável binária $B O V$, que assume valor igual a 1 (um) se a empresa está listada nos Níveis Diferenciados de Governança Corporativa ou no Novo Mercado da Bovespa e assume valor igual a 0 (zero) caso contrário.

\subsection{População, amostragem e coleta de dados}

A amostra do estudo é composta por todas companhias abertas não-financeiras negociadas na Bolsa de Valores de São Paulo - Bovespa que apresentaram liquidez significativa em 2002. Considerou-se como empresas com liquidez significativa as empresas que apresentaram índice de liquidez anual calculado pelo Economática ${ }^{\circledR}$ maior que $0,001 \%$ do índice correspondente à empresa com maior liquidez. A escolha desta faixa de corte se deve ao fato de que as ações de empresas com liquidez muito baixa possuem uma probabilidade menor de terem suas cotações adequadas ao valor de mercado, sendo a cotação das ações necessária para o cálculo do Q de Tobin e do múltiplo PBV.

Durante a coleta dos dados, algumas empresas não apresentaram informações suficientes para a construção de todas as variáveis, reduzindo o tamanho da amostra para um total de 154 empresas. Embora esta amostra possua um tamanho significativo em relação ao total de empresas listadas na Bovespa, a rigor, seria necessária uma amostragem por um método probabilístico para a generalização dos resultados. Utilizaram-se dados secundários coletados junto aos sistemas de informações Economática ${ }^{\circledR}$ e Divulgação Externa da Comissão de Valores Mobiliários. Para reduzir a influência de eventuais outliers, todas as variáveis de controle, além das variáveis de valor, foram winsorizadas $^{12}$ em 2,5\% e 97,5\%, embora também as variáveis originais tenham sido utilizadas nas regressões. Para realização dos testes estatísticos, foram utilizados os programas Stata/SE 8.0, Eviews 4.0 e GiveWin 2.10 .

\section{Análise dos resultados}

\subsection{Estatísticas descritivas do índice de governança corporativa (IGOV)}

O índice de governança corporativa (IGOV) das empresas pertencentes à amostra apresenta as seguintes estatísticas descritivas:

\footnotetext{
${ }^{11}$ Esta separação das variáveis binárias de emissão de ADRs foi feita tendo em vista que a ADR Nível 1 dá acesso ao mercado de balcão enquanto que as ADRs Nível 2 e Nível 3 dão acesso aos mercados de bolsa.

${ }^{12} \mathrm{~A}$ winsorização, procedimento originalmente proposto pelo bioestatístico C. P. Winsor, consiste em aparar os valores extremos (abaixo ou acima dos percentis mínimos e máximos definidos), substituindo-os pelos valores menores e maiores remanescentes na distribuição. Este procedimento foi utilizado em estudos recentes na área, como os de Black et alii (2006) e Durnev e Kim (2005).
} 
Tabela 1

Estatísticas descritivas do índice de governança corporativa (IGOV)

\begin{tabular}{ccccccccc}
\hline Variável & Média & Desvio-Padrão & Mínimo & $\begin{array}{c}1^{0} \\
\text { quartil }\end{array}$ & Mediana & $\begin{array}{c}3^{0} \\
\text { quartil }\end{array}$ & Máximo & $\begin{array}{c}\text { Amostra } \\
\text { (empresas) }\end{array}$ \\
\hline IGOV & 6,82 & 3,56 & 1,00 & 4,00 & 6,00 & 9,00 & 16,00 & 154 \\
\hline
\end{tabular}

Segundo a Tabela 1, o IGOV médio foi de 6,82, com $75 \%$ das empresas apresentando índice igual ou inferior a 9 . O valor médio obtido para IGOV pode ser considerado baixo, tendo em vista a aplicação de diversas questões que versavam sobre aspectos básicos de acesso às informações e transparência. A tabela a seguir apresenta o percentual de empresas cujas respostas foram positivas ("sim") para cada pergunta do índice.

Tabela 2

Percentual de empresas com respostas positivas ("sim") às questões do IGOV

\begin{tabular}{|c|c|c|}
\hline$\#$ & Pergunta do índice de governança (IGOV) & $\begin{array}{c}\% \text { de empresas com } \\
\text { respostas positivas ("sim") }\end{array}$ \\
\hline 1 & É possível obter o Relatório Anual (RA) da companhia via Internet? & $46,10 \%$ \\
\hline 2 & O website dispõe de documentos relativos a governança corporativa? & $16,90 \%$ \\
\hline 3 & $\begin{array}{l}\text { O website dispõe de apresentações para analistas ou dados que possibi- } \\
\text { litem projeções operacionais e financeiras da empresa? }\end{array}$ & $36,40 \%$ \\
\hline 4 & $\begin{array}{l}\text { O website é bilíngüe e possui uma seção de Relações com os Investido- } \\
\text { res? }\end{array}$ & $41,60 \%$ \\
\hline 5 & $\begin{array}{l}\text { Não houve necessidade de contato direto com a companhia para } \\
\text { obtenção de informações sobre a empresa? }\end{array}$ & $48,10 \%$ \\
\hline 6 & $\begin{array}{l}\text { O RA inclui uma seção específica dedicada à implementação de } \\
\text { princípios de Governança? }\end{array}$ & $23,40 \%$ \\
\hline 7 & $\begin{array}{l}\text { O RA ou outro documento explica a remuneração global dos executi- } \\
\text { vos? }\end{array}$ & $15,60 \%$ \\
\hline 8 & Os demonstrativos são apresentados em US-GAAP ou IAS-GAAP? & $19,50 \%$ \\
\hline 9 & $\begin{array}{l}\text { O RA ou website inclui uma seção com estimativas de lucros ou } \\
\text { projeções de retornos financeiros (ROA, ROE, etc.)? }\end{array}$ & $1,90 \%$ \\
\hline 10 & $\begin{array}{l}\text { O RA ou algum outro documento corporativo apresenta o valor adici- } \\
\text { onado/destruído pelo negócio no período com base em alguma medida } \\
\text { de lucro econômico? }\end{array}$ & $3,90 \%$ \\
\hline 11 & $\begin{array}{l}\text { Os cargos de Diretor Executivo e Presidente do conselho de } \\
\text { administração (CA) são ocupados por pessoas diferentes? }\end{array}$ & $63,00 \%$ \\
\hline 12 & A empresa possui um CA com 5 a 9 membros? & $62,30 \%$ \\
\hline 13 & Mais do que $80 \%$ do CA é composto por conselheiros externos? & $55,80 \%$ \\
\hline 14 & O conselho de administração possui mandato unificado de um ano? & $22,70 \%$ \\
\hline 15 & A empresa não possui Acordo de Acionistas. & $69,50 \%$ \\
\hline 16 & A empresa emite apenas ações com direito a voto $(\mathrm{ON})$ ? & $12,30 \%$ \\
\hline 17 & As preferenciais correspondem a menos que $50 \%$ do total de ações? & $37,70 \%$ \\
\hline 18 & O controlador possui menos do que $70 \%$ do total de ordinárias? & $38,30 \%$ \\
\hline 19 & $\begin{array}{l}\text { O excesso (DIF) de direitos de voto (\%ON) em relação aos direitos } \\
\text { sobre o fluxo de caixa (\%TA) do controlador é menor que } 23 \% \text { ? }\end{array}$ & $51,30 \%$ \\
\hline 20 & A empresa concede tag along aos detentores de ações preferenciais? & $16,20 \%$ \\
\hline
\end{tabular}


Os resultados da Tabela 2 mostram que menos da metade $(46,1 \%)$ das empresas disponibilizam seus relatórios anuais via Internet para os investidores e que apenas $16,9 \%$ disponibilizam no seu website documentos relativos ao modelo e práticas de governança corporativa adotadas. Ademais, percebe-se um conteúdo relativamente pobre dos Relatórios Anuais, principalmente em termos de explicação sobre as práticas de governança implementadas $(23,4 \%)$ e sobre a política de remuneração dos executivos $(15,6 \%)$. Constatou-se ainda que menos de um quinto $(19,5 \%)$ das empresas apresenta os demonstrativos financeiros convertidos para normas contábeis internacionais (US-GAAP ou IAS-GAAP). Como destaque negativo, observou-se uma ausência quase completa de empresas que mostram o resultado do período com base em alguma métrica de valor adicionado baseada no lucro econômico $(3,9 \%)$. Tendo em vista que a principal função dos gestores é gerar valor para os acionistas, essa constatação pode ser considerada surpreendente, já que raramente as companhias reportam se estão criando ou destruindo valor para os acionistas. Com relação à estrutura do conselho de administração observou-se, em linhas gerais, que as empresas possuem um conselho adequado (ao menos formalmente) às práticas recomendadas de governança, com pessoas diferentes ocupando os cargos de diretor executivo e presidente do conselho $(63,0 \%)$, conselhos compostos por cinco a nove membros $(62,3 \%)$ e por grande maioria de externos $(55,8 \%)$. A emissão exclusiva de ações ordinárias é pouco freqüente entre as companhias $(12,3 \%)$, bem como a concessão de tag along aos detentores de ações preferenciais $(16,3 \%)$ pelas empresas emissoras de duas classes de ações.

\subsection{Correlações e relações preliminares entre qualidade da governança e va- lor das empresas}

A matriz de correlações das variáveis utilizadas no estudo é apresentada na tabela a seguir: 
Tabela 3
Matriz de correlações das variáveis (amostra de 154 empresas para o ano de 2002

\begin{tabular}{|c|c|c|c|c|c|c|c|c|c|c|c|c|c|}
\hline & $\mathbf{Q}$ & PBV & IGOV & CON & DIVPL & ADR1 & ADR23 & BOV & LogREC & LIQ & $\overline{\text { LAJIRDA }}$ & TANG & CREC \\
\hline $\mathbf{Q}$ & 1 & & & & & & & & & & & & \\
\hline \multicolumn{14}{|l|}{ sig. (bi-caudal) } \\
\hline PBV & 0,5658 & 1 & & & & & & & & & & & \\
\hline sig. (bi-caudal) & 0,0000 & & & & & & & & & & & & \\
\hline IGOV & 0,2578 & 0,3728 & 1 & & & & & & & & & & \\
\hline sig. (bi-caudal) & 0,0015 & 0,0000 & & & & & & & & & & & \\
\hline CON & 0,1548 & 0,0384 & $-0,2318$ & 1 & & & & & & & & & \\
\hline sig. (bi-caudal) & 0,0594 & 0,6474 & 0,0038 & & & & & & & & & & \\
\hline DIVPL & 0,3532 & 0,2495 & $-0,0870$ & 0,0265 & 1 & & & & & & & & \\
\hline sig. (bi-caudal) & 0,0000 & 0,0031 & 0,2912 & 0,7480 & & & & & & & & & \\
\hline ADR1 & 0,0291 & $-0,1000$ & 0,0612 & 0,0699 & $-0,0735$ & 1 & & & & & & & \\
\hline sig. (bi-caudal) & 0,7251 & 0,2332 & 0,4511 & 0,3893 & 0,3733 & & & & & & & & \\
\hline ADR23 & 0,2881 & 0,2742 & 0,5223 & $-0,1488$ & $-0,1186$ & $-0,2075$ & 1 & & & & & & \\
\hline sig. (bi-caudal) & 0,0004 & 0,0009 & 0,0000 & 0,0656 & 0,1496 & 0,0098 & & & & & & & \\
\hline BOV & 0,0315 & 0,2380 & 0,2827 & 0,0264 & $-0,0363$ & 0,1082 & 0,2281 & 1 & & & & & \\
\hline sig. (bi-caudal) & 0,7033 & 0,0041 & 0,0004 & 0,7453 & 0,6603 & 0,1816 & 0,0044 & & & & & & \\
\hline LogREC & 0,2066 & 0,3291 & 0,5455 & $-0,1082$ & $-0,0386$ & 0,0453 & 0,3903 & 0,1914 & 1 & & & & \\
\hline sig. (bi-caudal) & 0,0118 & 0,0001 & 0,0000 & 0,1829 & 0,6402 & 0,5781 & $\mathbf{0 , 0 0 0 0}$ & 0,0178 & & & & & \\
\hline LIQ & 0,2252 & 0,1635 & 0,4332 & $-0,1469$ & $-0,0892$ & $-0,1083$ & 0,592 & 0,1457 & 0,4712 & 1 & & & \\
\hline sig. (bi-caudal) & 0,0057 & 0,0503 & 0,0000 & 0,0691 & 0,2795 & 0,1811 & 0,0000 & 0,0714 & 0,0000 & & & & \\
\hline LAJIRDA & 0,0311 & 0,2804 & 0,1531 & $-0,0997$ & $-0,1229$ & $-0,1881$ & 0,1158 & $-0,0690$ & 0,3729 & 0,0686 & 1 & & \\
\hline sig. (bi-caudal) & 0,7131 & 0,0009 & 0,0641 & 0,2294 & 0,1424 & 0,0225 & 0,1626 & 0,4064 & 0,0000 & 0,4093 & & & \\
\hline TANG & 0,1474 & $-0,1166$ & 0,1560 & 0,089 & $-0,0510$ & 0,1828 & 0,0993 & 0,0621 & 0,0947 & 0,2029 & $-0,2221$ & 1 & \\
\hline sig. (bi-caudal) & 0,0728 & 0,1639 & 0,0534 & 0,2726 & 0,5366 & 0,0273 & 0,2204 & 0,4446 & 0,2445 & 0,0106 & $\overline{0,0069}$ & & \\
\hline CREC & 0,1578 & 0,2213 & 0,2740 & 0,0443 & $-0,0759$ & $-0,0661$ & 0,2874 & 0,0458 & 0,3934 & 0,2352 & 0,2791 & 0,1686 & 1 \\
\hline sig. (bi-caudal) & 0,0666 & 0,0011 & 0,0010 & 0,6019 & 0,3744 & 0,4362 & 0,0005 & 0,5900 & $\overline{0,0000}$ & 0,0050 & 0,0010 & 0,0456 & \\
\hline
\end{tabular}


Observa-se na Tabela 3 uma correlação positiva significante no nível de $1 \%$ entre IGOV e as variáveis de valor Q de Tobin e PBV. Outra relação preliminar e qualitativa entre as variáveis pode ser observada pelas seguintes figuras:

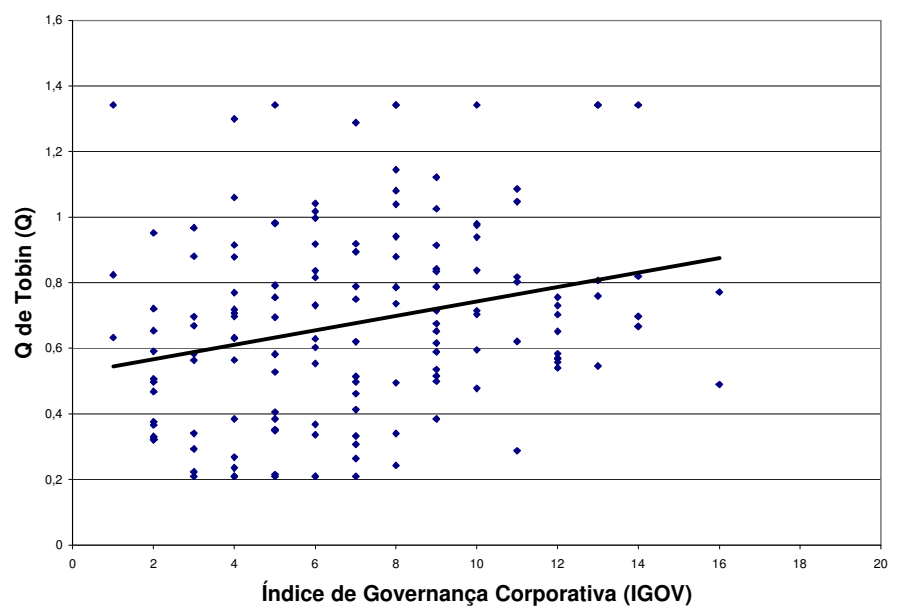

Figura 1

Relação preliminar entre governança corporativa (IGOV) e Q de Tobin (Q)

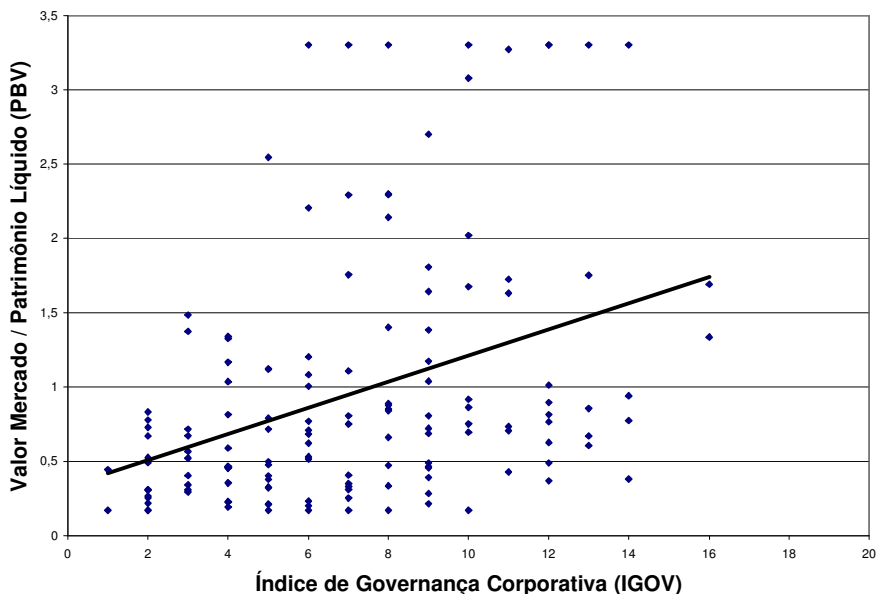

Figura 2

Relação preliminar entre governança corporativa (IGOV) e múltiplo PBV (PBV)

A figura mostra uma relação positiva entre as variáveis (as retas representam 
regressões simples estimadas por MQO). Entretanto, a relação de causalidade de IGOV para Q e PBV depende da aplicação de técnicas econométricas mais adequadas.

\subsection{Resultado utilizando regressões múltiplas, variáveis instrumentais e sis- temas de equações simultâneas}

Para avaliar a relação entre IGOV e valor das empresas, inicialmente foram computadas regressões múltiplas utilizando o procedimento de mínimos quadrados ordinário (MQO). Os resultados das regressões por MQO com diferentes especificações do modelo empírico são apresentados a seguir:

Tabela 4

Relação entre governança corporativa (IGOV) e valor das empresas (Q e PBV) por MQO

\begin{tabular}{|c|c|c|c|c|c|c|}
\hline & \multicolumn{3}{|c|}{ Q de Tobin } & \multicolumn{3}{|c|}{ PBV } \\
\hline $\begin{array}{l}\text { Variáveis } \\
\text { independentes }\end{array}$ & (1) & (2) & (3) & (1) & (2) & (3) \\
\hline IGOV & $\begin{array}{c}0,015^{* * *} \\
(2,07) \\
\end{array}$ & $\begin{array}{c}0,017 * * \\
(2,14) \\
\end{array}$ & $\begin{array}{l}0,009 \\
(1,06) \\
\end{array}$ & $\begin{array}{c}0,079 * * * \\
(3,72) \\
\end{array}$ & $\begin{array}{c}0,069 \text { **** } \\
(3,44) \\
\end{array}$ & $\begin{array}{c}0,058^{* * *} \\
(2,50) \\
\end{array}$ \\
\hline $\mathrm{CON}$ & $\overline{-}$ & $\begin{array}{c}0,367 \text { **** } \\
(3,14) \\
\end{array}$ & $\begin{array}{c}0,356 * * * \\
(3,07) \\
\end{array}$ & - & $\begin{array}{c}0,650^{* *} \\
(2,16) \\
\end{array}$ & $\begin{array}{l}0,533 \\
(1,60)\end{array}$ \\
\hline DIVPL & - & $\begin{array}{c}0,036^{* * * *} \\
(5,04) \\
\end{array}$ & $\begin{array}{c}0,040 * * * \\
(5,38) \\
\end{array}$ & - & $\begin{array}{c}0,076^{* *} \\
(2,12) \\
\end{array}$ & $\begin{array}{c}0,072^{* *} \\
(2,04) \\
\end{array}$ \\
\hline$\overline{\text { LIQ }}$ & - & $\begin{array}{l}0,052 \\
(1,61) \\
\end{array}$ & $\begin{array}{l}0,027 \\
(0,69) \\
\end{array}$ & - & $\begin{array}{l}-0,018 \\
(-0,23) \\
\end{array}$ & $\begin{array}{l}-0,069 \\
(-0,82) \\
\end{array}$ \\
\hline PAYOUT & - & $\begin{array}{l}0,000 \\
(0,03) \\
\end{array}$ & $\begin{array}{l}0,000 \\
(0,71) \\
\end{array}$ & - & $\begin{array}{l}-0,001 \\
(-0,72) \\
\end{array}$ & $\begin{array}{l}-0,001 \\
(-0,61) \\
\end{array}$ \\
\hline LAJIRDA & - & $\begin{array}{l}0,182 \\
(0,49) \\
\end{array}$ & $\begin{array}{l}0,203 \\
(0,53) \\
\end{array}$ & - & $\begin{array}{l}1,368 \\
(1,42) \\
\end{array}$ & $\begin{array}{l}1,382 \\
(1,42) \\
\end{array}$ \\
\hline$\overline{\mathrm{CREC}}$ & - & $\begin{array}{l}0,000 \\
(0,01) \\
\end{array}$ & $\begin{array}{l}-0,018 \\
(-0,40) \\
\end{array}$ & - & $\begin{array}{l}0,180 \\
(1,21) \\
\end{array}$ & $\begin{array}{l}0,142 \\
(1,03) \\
\end{array}$ \\
\hline $\log ($ REC $)$ & - & $\begin{array}{l}0,023 \\
(0,45)\end{array}$ & $\begin{array}{l}-0,043 \\
(-0,79)\end{array}$ & - & $\begin{array}{l}0,212 \\
(1,60)\end{array}$ & $\begin{array}{l}0,178 \\
(1,16)\end{array}$ \\
\hline TANG & - & $\begin{array}{c}0,053^{* * *} \\
(2,04)\end{array}$ & $\begin{array}{l}0,029 \\
(0,90)\end{array}$ & - & $\begin{array}{c}-0,167 * * \\
(-2,26)\end{array}$ & $\begin{array}{l}-0,126 \\
(-1,42) \\
\end{array}$ \\
\hline ADR1 & - & - & $\begin{array}{l}0,108 \\
(1,32) \\
\end{array}$ & - & - & $\begin{array}{l}-0,247 \\
(-1,13) \\
\end{array}$ \\
\hline ADR23 & - & - & $\begin{array}{c}0,191 * * * \\
(2,18)\end{array}$ & - & - & $\begin{array}{l}0,136 \\
(0,50)\end{array}$ \\
\hline $\mathrm{BOV}$ & - & - & $\begin{array}{l}0,039 \\
(0,59)\end{array}$ & - & $\overline{-}$ & $\begin{array}{c}0,432^{* *} \\
(2,12)\end{array}$ \\
\hline $\begin{array}{l}\text { Dummies } \\
\text { IDENT }\end{array}$ & NÃO & NÃO & SIM & NÃO & NÃO & SIM \\
\hline $\begin{array}{l}\text { Dummies } \\
\text { IND }\end{array}$ & SIM & SIM & SIM & SIM & SIM & SIM \\
\hline Intercepto & $\begin{array}{c}0,617 \text { **** } \\
(83,26)\end{array}$ & $\begin{array}{l}0,385 \\
(1,20)\end{array}$ & $\begin{array}{l}0,367 \\
(1,21)\end{array}$ & $\begin{array}{c}0,364 * * * \\
(17,19)\end{array}$ & $\begin{array}{l}-1,589 \\
(-2,07) \\
\end{array}$ & $\begin{array}{l}-1,507 \\
(-1,55) \\
\end{array}$ \\
\hline $\mathrm{R}^{2}$ & $19,97 \%$ & $42,30 \%$ & $44,95 \%$ & $20,27 \%$ & $38,53 \%$ & $44,90 \%$ \\
\hline Amostra (n) & 148 & 128 & 128 & 143 & 123 & 123 \\
\hline $\begin{array}{l}\text { As variáveis de } \\
\text { interesse é o ín } \\
\text { números entre } \\
\text { nos níveis de } 19 \\
\text { (IND) das emp } \\
\text { coeficientes for }\end{array}$ & $\begin{array}{l}\text { dentes sã } \\
\text { de gover } \\
\text { ateses ind } \\
\text { \% e } 10 \% \text {, } \\
\text { nas regr } \\
\text { stimados }\end{array}$ & $\begin{array}{l}2 \text { de Tobi } \\
\text { ca corpor: } \\
\text { a estatís } \\
\text { ectivame } \\
\text { es, as qu }\end{array}$ & $\begin{array}{l}\text { o múltip } \\
\text { (IGOV } \\
\text { t. ***, } \\
\text { Incluíra } \\
\text { foram on }\end{array}$ & $\begin{array}{l}\text { PBV, enqu } \\
\text { s dados sã } \\
\text { * corresp } \\
\text { se variáveis } \\
\text { das da tab }\end{array}$ & $\begin{array}{l}\text { a variáv } \\
\text { lativos a } \\
\text { em à sign } \\
\text { árias par } \\
\text { or limita }\end{array}$ & $\begin{array}{l}\text { ndependente de } \\
\text { to de } 2002 \text {. Os } \\
\text { ância estatística } \\
\text { setor de atuação } \\
\text { de espaço. Os } \\
\text { ocedasticidade. }\end{array}$ \\
\hline
\end{tabular}


A especificação 1 consistiu na aplicação de um modelo de regressão controlando apenas as diferenças setoriais entre as empresas (variáveis binárias setoriais). Este modelo indicou uma relação positiva significante no nível de 5\% entre IGOV e Q e significante no nível de $1 \%$ entre IGOV e PBV. A especificação 2 é considerada o modelo-base do estudo, representado pela Equação 2, no qual figuram diversas variáveis de controle. Os resultados desta especificação também indicaram uma relação positiva significante no nível de 5\% entre IGOV e Q e significante no nível de $1 \%$ entre IGOV e PBV. A magnitude do coeficiente de IGOV $(0,017)$ informa que uma mudança na qualidade da governança corporativa do pior para o melhor nível (aumentando IGOV de 1 para 16) resultaria em um aumento de 0,25 do Q de Tobin da empresa em questão. Caso a empresa tivesse um $\mathrm{Q}$ de Tobin igual ao Q médio da amostra $(0,68)$ e uma relação dívida total/ativo total igual à média da amostra $(0,39)$, o aumento na qualidade da governança preveria um aumento da capitalização de mercado da empresa de cerca de $85 \%$, ceteris paribus. Com relação à variável PBV, a magnitude do seu coeficiente $(0,069)$ informa que uma mudança na qualidade da governança corporativa do pior para o melhor nível resultaria em um aumento de 1,03 do múltiplo PBV da empresa em questão. Caso a empresa tivesse um múltiplo PBV igual ao PBV médio da amostra $(1,03)$, o aumento na qualidade da governança preveria uma valorização das ações de cerca de $100 \%$, ceteris paribus. Independentemente da variável de valor utilizada, o modelo-base da pesquisa prevê um incremento substancial do valor das empresas em caso de aprimoramento das práticas de governança corporativa. A especificação 3 utilizou adicionalmente variáveis relativas a emissão de ADRs, adesão aos níveis de governança corporativa da Bovespa e identidade dos acionistas controladores. Nesta especificação, houve perda de significância da variável IGOV quando Q é a variável dependente e diminuição do nível de significância estatística quando a variável dependente é PBV. Este resultado deve-se principalmente à inclusão da variável de emissão de ADRs Nível 2 ou Nível 3 ( $A D R 23$ ), o que não é surpreendente, considerando-se que a emissão de ADRs em mercado de bolsa também pode ser vista como uma aproximação para boas práticas de governança (já que as empresas se comprometem com uma maior transparência e com padrões mais rígidos de proteção ao investidor). 
Em todas as regressões por MQO foram computados erros-padrão robustos a heterocedasticidade com correção para amostras finitas. Em algumas regressões, foram excluídas variáveis setoriais binárias que apresentavam problemas de multicolinearidade (medido pelo FIV - fator de inflação da variância. ${ }^{13}$ ) Estas variáveis se mostravam redundantes e prejudicavam a estabilidade numérica das estimativas. Foram realizadas regressões alternativas sem a presença de outliers, identificados com base nos resíduos estudentizados das regressões, com manutenção dos principais resultados. Um potencial problema na estimação por MQO é a possibilidade de ocorrência do viés de variáveis omitidas, conforme descrito na seção 3.1. Como forma de avaliar se o problema de variáveis omitidas é aparente, foram realizados testes de Ramsey (RESET). Os testes não rejeitaram a hipótese nula de não existência de variável omitida no modelo, conferindo maior credibilidade às estimativas obtidas por MQO.

Em seguida, foram realizadas regressões pelo procedimento MQ2E. Conforme discussão metodológica apresentada na subseção 3.1, foram escolhidos cinco instrumentos a serem utilizados alternativamente ou em conjunto para a variável de governança corporativa: 1) emissão de ADR Nível 1 ( $A D R 1)$; 2) emissão de ADR Nível 2 ou 3 ( $A D R 23) ; 3$ ) adesão aos níveis de governança corporativa da Bovespa $(B O V)$; 4) variável binária de tamanho da empresa $(D T A M)$; e 5) identidade do acionista controlador $(I D E N T)$. Os resultados das regressões por MQ2E com diferentes especificações do modelo são apresentados abaixo:

\footnotetext{
${ }^{13}$ Foram excluídas todas as variáveis com FIVs acima de 20. É importante destacar que todas as variáveis excluídas eram dummies setoriais que se mostravam redundantes no modelo de regressão.
} 
Tabela 5

Relação entre governança corporativa (IGOV) e valor das empresas (Q e PBV) por MQ2E

\begin{tabular}{|c|c|c|c|c|c|c|}
\hline & \multicolumn{6}{|c|}{ Estimação por MQ2E para Q de Tobin } \\
\hline & \multicolumn{2}{|c|}{ Especificação (1) } & \multicolumn{2}{|c|}{ Especificação (2) } & \multicolumn{2}{|c|}{ Especificação (3) } \\
\hline & $1^{\circ}$ Estágio & $2^{\circ}$ Estágio & $1^{\circ}$ Estágio & $2^{\circ}$ Estágio & $1^{0}$ Estágio & $2^{0}$ Estágio \\
\hline & IGOV & Q Tobin & IGOV & Q Tobin & IGOV & Q Tobin \\
\hline IGOV Instrumentado & - & $\begin{array}{c}0,080^{* * *} \\
(2,30)\end{array}$ & - & $\begin{array}{l}0,078^{*} \\
(1,82)\end{array}$ & - & $\begin{array}{c}0,055^{* * *} \\
(2,06)\end{array}$ \\
\hline ADR1 & $\begin{array}{l}0,803 \\
(0,98) \\
\end{array}$ & - & - & - & $\begin{array}{l}0,775 \\
(0,97)\end{array}$ & - \\
\hline ADR23 & $\begin{array}{c}2,924 * * * \\
(2,66)\end{array}$ & - & - & - & $\begin{array}{c}3,088^{*} * * \\
(2,75)\end{array}$ & - \\
\hline BOV & $\begin{array}{l}0,968 \\
(1,51)\end{array}$ & - & - & - & $\begin{array}{l}0,979 \\
(1,40)\end{array}$ & - \\
\hline DTAM & $\begin{array}{l}1,318 \\
(1,52)\end{array}$ & - & $\begin{array}{l}1,244 \\
(1,43)\end{array}$ & - & - & - \\
\hline Dummies IDENT & NÅO & - & $\overline{\text { SIM }}$ & $\overline{-}$ & $\overline{\text { SIM }}$ & $\overline{-}$ \\
\hline $\log (\mathrm{REC})$ & $\begin{array}{c}1,580^{* * *} \\
(2,30)\end{array}$ & $\begin{array}{l}-0,158 \\
(-1,51)\end{array}$ & $\begin{array}{c}2,298 * * * \\
(3,40)\end{array}$ & $\begin{array}{l}-0,152 \\
(-1,15)\end{array}$ & $\begin{array}{c}2,344 * * * \\
(4,05)\end{array}$ & $\begin{array}{l}-0,085 \\
(-0,99)\end{array}$ \\
\hline Outras Var. Controle & SIM & $\overline{\text { SIM }}$ & $\overline{\text { SIM }}$ & SIM & SIM & $\overline{\text { SIM }}$ \\
\hline Dummies IND & SIM & SIM & SIM & SIM & SIM & SIM \\
\hline Amostra (n) & 128 & 128 & 128 & 128 & 128 & 128 \\
\hline Prob $>F$ & 0,0000 & 0,0000 & 0,0000 & 0,0000 & 0,0000 & 0,0000 \\
\hline
\end{tabular}

\begin{tabular}{|c|c|c|c|c|c|c|}
\hline & \multicolumn{6}{|c|}{ Estimação por MQ2E para PBV } \\
\hline & \multicolumn{2}{|c|}{ Especificação (1) } & \multicolumn{2}{|c|}{ Especificação (2) } & \multicolumn{2}{|c|}{ Especificação (3) } \\
\hline & $1^{\circ}$ Estágio & $2^{\circ}$ Estágio & $1^{\circ}$ Estágio & $2^{\circ}$ Estágio & $1^{\circ}$ Estágio & $2^{\circ}$ Estágio \\
\hline & IGOV & PBV & IGOV & PBV & IGOV & PBV \\
\hline IGOV Instrumentado & - & $\begin{array}{c}0,165^{* * *} \\
(2,49)\end{array}$ & - & $\begin{array}{l}0,099 \\
(1,13)\end{array}$ & - & $\begin{array}{c}0,120^{* *} \\
(1,99)\end{array}$ \\
\hline ADR1 & $\begin{array}{l}1,074 \\
(1,26)\end{array}$ & - & - & - & $\begin{array}{l}1,059 \\
(1,28)\end{array}$ & - \\
\hline ADR23 & $\begin{array}{c}3,073^{* * * *} \\
(2,82)\end{array}$ & - & - & - & $\begin{array}{c}3,267 * * * \\
(2,94)\end{array}$ & - \\
\hline BOV & $\begin{array}{l}0,986 \\
(1,53)\end{array}$ & - & - & - & $\begin{array}{l}0,966 \\
(1,35)\end{array}$ & - \\
\hline DTAM & $\begin{array}{l}1,339 \\
(1,55)\end{array}$ & - & $\begin{array}{l}1,375 \\
(1,55)\end{array}$ & - & - & - \\
\hline Dummies IDENT & NÃO & - & SIM & - & SIM & - \\
\hline $\log (\mathrm{REC})$ & $\begin{array}{c}1,481^{* * *} \\
(2,09)\end{array}$ & $\begin{array}{l}-0,076 \\
(-0,34)\end{array}$ & $\begin{array}{c}2,298 * * * \\
(3,21)\end{array}$ & $\begin{array}{l}0,120 \\
(0,42)\end{array}$ & $\begin{array}{c}2,299 * * * \\
(3,79)\end{array}$ & $\begin{array}{l}0,057 \\
(0,26)\end{array}$ \\
\hline Outras Var. Controle & SIM & SIM & SIM & SIM & SIM & SIM \\
\hline Dummies IND & SIM & SIM & SIM & SIM & SIM & SIM \\
\hline Amostra (n) & 123 & 123 & 123 & 123 & 123 & 123 \\
\hline Prob $>F$ & 0,0000 & 0,0000 & 0,0000 & 0,0000 & 0,0000 & 0,0000 \\
\hline
\end{tabular}

Regressão de Q de Tobin e múltiplo PBV contra IGOV estimada pelo método dos mínimos quadrados de dois estágios (MQ2E) com erros-padrão robustos a heterocedasticidade. Foram utilizadas cinco variáveis instrumentais: ADR1, ADR23, BOV, DTAM e IDENT. O primeiro estágio consiste na regressão de IGOV contra todas as outras variáveis exógenas, incluindo os instrumentos. O segundo estágio é estimado utilizando os valores ajustados de IGOV obtidos no primeiro estágio. Nas regressões, foram incluídas todas as variáveis de controle utilizadas no modelo-base (especificação 2 da Tabela 4), incluindo as variáveis binárias setoriais. Essas variáveis de controle, com exceção da variável de porte da empresa $(\log (\operatorname{REC}))$, foram omitidas da tabela por limitação de espaço. Os números entre parênteses indicam a estatística t. ***, ** e * correspondem à significância estatística nos níveis de $1 \%, 5 \%$ e $10 \%$. 
Os resultados foram obtidos pela aplicação do estimador MQ2E com errospadrão robustos a heterocedasticidade e à correlação contemporânea dos erros. Por conservadorismo, os valores críticos adotados para se inferir sobre a significância estatística dos coeficientes basearam-se na distribuição t de Student ao invés da distribuição Normal. Para avaliar a adequação dos instrumentos utilizados, utilizou-se o teste de restrições de sobre-identificação de Hansen. Este teste avalia a plausibilidade estatística da suposição de exogeneidade dos instrumentos. A hipótese nula conjunta é que: i) os instrumentos escolhidos para IGOV são nãocorrelacionados com o termo de erro e ii) a exclusão dos instrumentos da regressão que determina Q de Tobin e PBV é aceitável. A não-rejeição da hipótese nula, portanto, sugere que os instrumentos são adequados. ${ }^{14}$ Em todas as especificações, a estatística J de Hansen apresentou um nível descritivo ( $p$-value) superior a 0,10 , não rejeitando a hipótese nula nos níveis de significância usuais e fornecendo alguma evidência de que os instrumentos escolhidos são aceitáveis, do ponto de vista estatístico.

Os resultados apresentados na Tabela 5 indicam uma relação positiva significante no nível de 5\% entre IGOV e Q e entre IGOV e PBV, robusta a diferentes especificações de modelos e conjuntos de instrumentos. Por fim, foram computados testes de Durbin-Wu-Hausman (DWH) para avaliar a plausibilidade estatística da hipótese de exogeneidade de IGOV (uma vez que a suposição de não-validade desta hipótese motiva a preferência pelo método MQ2E). Trata-se de um teste de consistência do estimador MQO, comparando as estimativas obtidas utilizando-se este método com aquelas obtidas utilizando-se um estimador de variáveis instrumentais (VI). A hipótese nula é que os dois estimadores são consistentes. Desta forma, se não houver rejeição da mesma, deve-se preferir a estimação por MQO, mais eficiente. Todos os testes DWH rejeitaram a hipótese nula nos níveis de significância usuais, corroborando a suposição de que IGOV é uma variável endógena e que estimadores de variáveis instrumentais são mais adequadas (assumindo que os instrumentos são válidos). Foram, ainda, realizadas regressões adicionais com o mesmo conjunto de instrumentos, porém utilizando um procedimento de estimação baseado no método dos momentos generalizado (MMG). Os resultados por MMG mostraram-se similares aos obtidos por MQ2E e não são reportados por economia de espaço.

${ }^{14} \mathrm{O}$ teste de Hansen é similar ao teste mais conhecido de Sargan, porém, ao contrário deste último, é robusto a heterocedasticidade. 
Após a análise com equações individuais, a relação entre IGOV e a variáveis de valor foi investigada por meio de sistemas de equações simultâneas estimados por mínimos quadrados de três estágios (MQ3E), pelo método dos momentos generalizado (MMG) e pelo método de máxima verossimilhança com informação completa (MVIC). ${ }^{15}$ Conforme a discussão metodológica da subseção 3.1, embora um sistema com mais equações pudesse ser estimado (levando em conta outras variáveis corporativas potencialmente endógenas), o presente estudo se concentrou na relação entre as variáveis de governança e de valor, que foi modelada pelo seguinte sistema (com Q ou PBV substituindo a variável VALOR):

$$
\begin{aligned}
& \text { VALOR } \text { A }_{01}+\beta_{11} I G O V_{i}+\beta_{21} C O N_{i}+\beta_{31} D I V P L_{i} \\
& +\beta_{41} L I Q_{i}+\beta_{51} P A Y O U T_{i}+\beta_{61} L A J I R D A_{i}+\beta_{71} C R E C_{i} \\
& +\beta_{81} \log (R E C)_{i}+\beta_{91} T A N G_{i}+\sum_{j=1}^{17} \delta_{j 1} I N D_{j i}+\varepsilon_{1 i} \\
& I G O V_{i}=\beta_{02}+\beta_{12} V A L O R_{i}+\beta_{22} C O N_{i}+\beta_{32} P A Y O U T_{i}+\beta_{42} L I Q_{i} \\
& +\beta_{52} L A J I R D A_{i}+\beta_{62} C R E C_{i}+\beta_{72} A D R 1_{i}+\beta_{82} A D R 23_{i} \\
& +\beta_{92} B O V_{i}+\beta_{102} \log (R E C)_{i}+\beta_{112} T A N G_{i}+\sum_{l=1}^{5} \gamma_{l 2} I D E N T_{l i} \\
& +\sum_{j=1}^{17} \delta_{j 2} I N D_{j i}+\varepsilon_{2 i}
\end{aligned}
$$

Os resultados das estimações por MQ3E utilizando a variável binária de tamanho (DTAM) como instrumento adicional ${ }^{16}$ são apresentados abaixo:

\footnotetext{
${ }^{15}$ A estimação do sistema de equações por diferentes métodos é importante devido às diferentes características e premissas de cada método de estimação. O estimador MQ3E assume homocedasticidade dos termos de erro, enquanto que as estimativas por MVIC e MMG são robustas a heterocedasticidade. Com relação às diferenças entre os métodos MVIC e MMG, o primeiro pressupõe a distribuição normal dos termos de erro, ao passo que o segundo não depende desta suposição. Embora a estimação por MMG seja mais robusta, caso a premissa de distribuição normal seja verdadeira a estimação pelo método MVIC pode ser mais eficiente.

${ }^{16}$ Além de DTAM, o procedimento MQ3E utiliza todas as variáveis de controle presentes na primeira equação, mas ausentes na segunda, como instrumentos para a segunda equação e vice-versa.
} 
Tabela 6

Relação entre governança corporativa (IGOV) e valor das empresas (Q e PBV) por MQ3E

\begin{tabular}{|c|c|c|}
\hline & Equação de valor & Equação de GC \\
\hline & \multicolumn{2}{|c|}{ Variável dependente da equação } \\
\hline & $\mathrm{Q}$ & IGOV \\
\hline IGOV & $\begin{array}{c}0,082^{* * * *} \\
(3,72)\end{array}$ & - \\
\hline Q & - & $\begin{array}{c}3,979 * * \\
(1,90)\end{array}$ \\
\hline Outras Var. Controle & SIM & SIM \\
\hline Dummies IND & SIM & SIM \\
\hline Amostra (n) & 128 & 128 \\
\hline \multirow[t]{4}{*}{ Prob $>F$} & 0,000 & 0,000 \\
\hline & Equação de valor & Equação de GC \\
\hline & \multicolumn{2}{|c|}{ Variável dependente da equação } \\
\hline & PBV & IGOV \\
\hline IGOV & $\begin{array}{c}0,174 * * * \\
(3,35)\end{array}$ & - \\
\hline PBV & - & $\begin{array}{l}1,090 \\
(0,72)\end{array}$ \\
\hline Outras Var. Controle & SIM & SIM \\
\hline Dummies IND & SIM & SIM \\
\hline Amostra (n) & 123 & 123 \\
\hline Prob $>F$ & 0,000 & 0,000 \\
\hline \multicolumn{3}{|c|}{$\begin{array}{l}\text { Sistemas de equações de valor e governança corporativa, conforme descri- } \\
\text { tos pela Equação } 4 \text {, estimados pelo método dos mínimos quadrados de três } \\
\text { estágios (MQ3E). Utilizou-se como instrumento adicional a variável binária } \\
\text { indicativa do porte da empresa (DTAM). Todas as variáveis de controle pre- } \\
\text { sentes na Equação } 4 \text { foram incluídas nas regressões e omitidas da tabela por } \\
\text { limitação de espaço. Os números entre parênteses indicam a estatística t. } \\
* * * * * \text { e * correspondem à significância estatística nos níveis de } 1 \%, 5 \% \text { e } \\
10 \% \text {, respectivamente. }\end{array}$} \\
\hline
\end{tabular}

Conforme os resultados reportados na Tabela 6, as regressões por MQ3E mostram uma influência positiva ainda mais forte de IGOV sobre Q e sobre PBV (significante no nível de 1\%). Os coeficientes de IGOV em ambos os sistemas (utilizando Q e PBV) são similares em magnitude aos obtidos nas regressões por MQ2E. Ademais, constatou-se uma relação positiva significante no nível de 5\% entre Q e IGOV e uma relação positiva não-significante entre PBV e IGOV na equação de governança. Estes resultados, principalmente na relação entre $\mathrm{Q}$ de Tobin e IGOV, apontam para uma relação de causalidade de mão-dupla, com a valorização das ações das empresas prevendo a adoção de melhores práticas de governança. As regressões pelos métodos MMG e MVIC, não reportadas por economia de espaço, corroboraram os resultados obtidos por MQ3E. Além de novamente indicarem uma influência positiva significante da qualidade da governança sobre as variáveis de valor, os resultados por MMG e MVIC também sugerem a existência de uma relação de causalidade de mão-dupla entre IGOV e as medidas de valor. Portanto, os resultados de uma forma geral indicam que as empresas que adotam melhores práticas de governança tendem a ser mais bem avaliadas pelo mercado, sugerindo que os seus padrões de governança são importantes do ponto de vista dos investidores e que investimentos em governança corporativa podem 
ser recompensadores economicamente. Por outro lado, há também indícios de que as empresas mais valorizadas são mais propensas a adotar melhores práticas de governança, possivelmente em razão de sua maior necessidade de captação externa, o que tornaria mais vantajoso o investimento em governança corporativa.

\section{Conclusão}

O objetivo principal do artigo é investigar a influência da qualidade da governança corporativa, mensurada por um índice de governança amplo (IGOV), sobre o valor de mercado (Q de Tobin e múltiplo PBV) das empresas abertas brasileiras. Esta investigação foi conduzida utilizando-se diferentes abordagens econométricas em ordem crescente de complexidade, incluindo regressões múltiplas por mínimos quadrados ordinário (MQO), estimadores de variáveis instrumentais (mínimos quadrados de dois estágios - MQ2E e método dos momentos generalizado - MMG) e sistemas de equações simultâneas (mínimos quadrados de três estágios - MQ3E, método dos momentos generalizado - MMG e máxima verossimilhança com informação completa - MVIC). Os resultados obtidos com todos os procedimentos mostram uma relação positiva e significante entre a qualidade da governança corporativa e as variáveis de valor. Ademais, os resultados sugerem que este efeito é causal, com o aumento na qualidade da governança corporativa (conforme definida no estudo) prevendo uma maior capitalização de mercado das empresas.

Inicialmente, foram computadas regressões pelo método MQO. Os resultados revelam uma relação positiva significante no nível de 5\% entre IGOV e Q de Tobin e significante a $1 \%$ entre IGOV e o múltiplo PBV. As estimações por MQO, entretanto, podem ser inconsistentes, devido à potencial endogeneidade da variável de governança corporativa. Por esta razão, novas regressões utilizando variáveis instrumentais foram estimadas por MQ2E e MMG. Foram escolhidos cinco instrumentos, utilizados em conjunto ou alternativamente: 1) emissão de ADR Nível 1;2) emissão de ADR Nível 2 ou Nível 3; 3) Adesão aos níveis de governança corporativa da Bovespa; 4) variável binária de tamanho da empresa; 5) Identidade do acionista controlador. A justificativa para utilização desses instrumentos é apresentada na seção 3.1. Os resultados indicaram uma relação positiva significante no nível de 5\% entre IGOV e Q e entre IGOV e PBV, robusta a diferentes especificações de modelos e instrumentos. Ademais, obteve-se evidências de que a variável de governança corporativa é endógena e que, portanto, as estimativas por MQO seriam inconsistentes.

$\mathrm{Na}$ seqüência, a relação entre IGOV e as variáveis de valor Q e PBV foi avaliada por meio de sistemas de equações simultâneas estimados por MQ3E, MMG e MVIC. Os procedimentos foram aplicados a sistemas compostos por duas equações, de forma a capturar a eventual presença de uma relação de causalidade de mão-dupla entre governança e valor. Os resultados obtidos mostram uma influência positiva ainda mais forte de IGOV sobre Q e sobre PBV (significante a $1 \%$ ). Ademais, os resultados sugerem que, assim como a qualidade da governança 
pode influenciar significativamente o valor das empresas, um aumento do valor de mercado também pode conduzir à adoção de melhores práticas de governança.

Os resultados reportados devem ser interpretados com cautela por dois motivos principais. O primeiro é o período de análise, considerando-se que apenas dados referentes ao ano de 2002 estavam disponíveis para a construção do índice IGOV. Esta característica da amostra inviabilizou a formulação de modelos dinâmicos e a análise dos padrões de comportamento intertemporal das variáveis de interesse, assim como a avaliação da estabilidade dos resultados ao longo do tempo e a aplicação de métodos potencialmente úteis de estimação apropriados para dados em painel. Até o presente momento, os estudos oferecidos por Leal e Carvalhal da Silva $(2005 b$,a) foram os únicos realizados no país com um índice de governança calculado para um período de tempo maior do que um ano. A segunda limitação diz respeito à dificuldade de obtenção de instrumentos claramente exógenos. A validade dos resultados reportados depende, em particular, das seguintes suposições: 1) os sistemas foram bem especificados; e 2) não há um problema sério de variáveis omitidas correlacionadas com os instrumentos utilizados. Como argumento de defesa da estratégia de investigação adotada, obteve-se evidências de que os instrumentos escolhidos são adequados (por meio do teste de restrições de sobre-identificação de Hansen) e de que não existem variáveis omitidas relevantes no modelo-base (por meio do teste RESET de Ramsey).

Os resultados da pesquisa são compatíveis com os reportados por Black (2001), Black et alii (2006), Durnev e Kim (2005), Bai et alii (2003), Beiner et alii (2004) e Brown e Caylor (2004), que também utilizaram índices amplos de governança e encontraram uma relação positiva e significante entre qualidade da governança corporativa e valor das empresas. Como sugestão para novos estudos, a busca por melhores instrumentos e o desenvolvimento de modelos formais (construídos a partir de teorias) passíveis de serem testados empiricamente são questões com grande potencial para pesquisa. Esta necessidade torna-se premente se considerarmos que os resultados das análises econométricas podem ser bastante sensíveis à especificação do sistema de equações e à escolha dos instrumentos.

\section{Referências}

Agrawal, A. \& Knoeber, C. (1996). Firm performance and mechanisms to control agency problems between managers and shareholders. Journal of Financial and Quantitative Analysis, 31:377-397.

Bai, C.-E., Liu, Q., Lu, J. Z., Song, F., \& Zhang, J. (2003). Corporate governance and market valuation in China. William Davidson Institute Working Paper No 564. Disponível em http://papers.ssrn.com/abstract_id=393440. Acesso em: 17 abr. 2006.

Barnhart, S. \& Rosenstein, S. (1998). Board composition, managerial ownership and firm performance: An empirical analysis. The Financial Review, (33):1-16. 
Beiner, S., Drobetz, W., Schimd, M., \& Zimmermann, H. (2004). An integrated framework of corporate governance and firm valuation - Evidence from Switzerland. ECGI finance working paper series, n. 34/2004. Disponível em http://papers.ssrn.com/abstract_id=489322Ȧcesso em: 17 abr. 2006.

Bhagat, S. \& Jefferis, R. (2002). The Econometrics of Corporate Governance Studies. Massachusetts Institute of Technology, 1st edition.

Black, B. (2001). The corporate governance behavior and market value of Russian firms. Emerging Markets Review, 2:89-108.

Black, B., Jang, H., \& Kim, W. (2006). Does corporate governance predict firms' market values? Evidence from Korea. Journal of Law, Economics, and Organization, 22(2).

Bøhren, Ø. \& Ødegaard, B. A. (2003). Governance and performance revisited. ECGI finance working paper, n. 28/2003. Disponível em http://ssrn.com/abstract_id=423461. Acesso em: 17 abr. 2006.

Brown, L. \& Caylor, M. (2004). Corporate governance and firm performance. NBER Working Paper. Disponível em http://papers.ssrn.com/ abstract_id=586423. Acesso em: 17 abr. 2006.

Cho, M.-H. (1998). Ownership structure, investment, and the corporate value: An empirical analysis. Journal of Financial Economics, 47:103-121.

Chung, K. \& Pruitt, S. (1994). A simple approximation of Tobin's Q. Financial Management, 23(3):70-74.

Claessens, S., Djankov, S., Fan, J., Lang, P. H., \& Larry, H. P. (2002). Disentangling the incentive and entrenchment effect of large shareholdings. The Journal of Finance, 57(6):2741-2771.

Demsetz, H. \& Villalonga, B. (2001). Ownership structure and corporate performance. Journal of Corporate Finance, 7:209-233.

Denis, D. \& McConnell, J. (2003). International corporate governance. Journal of Financial and Quantitative Analysis, 38(1):1-36.

Durnev, A. \& Kim, H. (2005). To steal or not to steal: Firm attributes, legal environment, and valuation. Journal of Finance, 60(3):1461-1493.

Himmelberg, C., Hubbard, G., \& Palia, D. (1999). Understanding the determinants of managerial ownership and the link between ownership and performance. Journal of Financial Economics, 53:353-384.

Klapper, L. \& Love, I. (2002). Corporate governance, investor protection, and performance in emerging markets. World Bank Policy Research Working Paper n. 2818. 
Leal, R. P. (2004). Governance practices and corporate value - A recent literature survey. Revista de Administração de Empresas da USP - RAUSP, 39(4):327337.

Leal, R. P. \& Carvalhal da Silva, A. L. (2005a). Corporate governance and value, in Brazil (and in Chile). Inter-American Development Bank, Latin American Research Network, Research Network Working Paper R-514, 2005. Disponível em http://www.iadb.org/res/pub_desc.cfm?pub_id=R-514. Acesso em: 17 abr. 2006.

Leal, R. P. \& Carvalhal da Silva, A. L. (2005b). Corporate governance index, firm valuation and performance in Brazil. Revista Brasileira de Finanças, 3(1):1-18.

Silveira, A. M., Barros, L. A., \& Famá, R. (2004a). Determinantes do nível de governança corporativa das companhias abertas brasileiras. IV Encontro Brasileiro de Finanças, Rio de Janeiro, 22 e 23 de julho, Anais...., 2004 (CD-ROM). Disponível em http://www.sbfin.org.br/. Acesso em: 25 set. 2004.

Silveira, A. M., Barros, L. A., \& Silveira, H. P. (2004b). Determinantes da concentração do direito de controle nas companhias abertas brasileiras. IV Encontro Brasileiro de Finanças, Rio de Janeiro, 22 e 23 de julho, Anais...., 2004 (CD-ROM). Disponível em http://www.sbfin.org.br/. Acesso em: 25 set. 2004. 


\section{Apêndice}

\section{Perguntas para Construção do Índice de Governança Corporativa (IGOV)}

Tabela A.1

\begin{tabular}{|c|c|c|}
\hline Dimensão de Governança & $\#$ & Pergunta do índice de governança (IGOV) \\
\hline \multirow[t]{5}{*}{ Acesso às Informações } & 1 & $\begin{array}{l}\text { É possível obter o Relatório Anual (RA) da companhia via } \\
\text { Internet? }\end{array}$ \\
\hline & 2 & $\begin{array}{l}\text { O website dispõe de documentos relativos a governança cor- } \\
\text { porativa? }\end{array}$ \\
\hline & 3 & $\begin{array}{l}\text { O website dispõe de apresentações para analistas ou dados } \\
\text { que possibilitem projeções operacionais e financeiras da em- } \\
\text { presa? }\end{array}$ \\
\hline & 4 & $\begin{array}{l}\text { O website é bilíngüe e possui uma seção de Relações com os } \\
\text { Investidores? }\end{array}$ \\
\hline & 5 & $\begin{array}{l}\text { Não houve necessidade de contato direto com a companhia } \\
\text { para obtenção de informações sobre a empresa? }\end{array}$ \\
\hline \multirow[t]{5}{*}{ Conteúdo das Informações Públicas } & 6 & $\begin{array}{l}\text { O RA inclui uma seção específica dedicada à implementação } \\
\text { de princípios de Governança Corporativa? }\end{array}$ \\
\hline & 7 & $\begin{array}{l}\text { O RA, website ou algum outro documento explica a } \\
\text { remuneração global dos executivos? }\end{array}$ \\
\hline & 8 & $\begin{array}{l}\text { Os demonstrativos são apresentados em US-GAAP ou IAS- } \\
\text { GAAP? }\end{array}$ \\
\hline & 9 & $\begin{array}{l}\text { O RA, website ou algum outro documento inclui uma seção } \\
\text { com estimativas de lucros ou projeções de retornos financei- } \\
\text { ros? }\end{array}$ \\
\hline & 10 & $\begin{array}{l}\text { O RA, website ou algum outro documento corporativo apre- } \\
\text { senta o valor adicionado/destruído pelo negócio no período } \\
\text { com base em alguma medida de lucro econômico? }\end{array}$ \\
\hline \multirow[t]{5}{*}{ Estrutura do conselho de administração } & 11 & $\begin{array}{l}\text { Os cargos de Diretor Executivo e Presidente do conselho de } \\
\text { administração são ocupados por pessoas diferentes? }\end{array}$ \\
\hline & 12 & $\begin{array}{l}\text { A empresa possui um conselho de administração com } 5 \text { a } 9 \\
\text { membros? }\end{array}$ \\
\hline & 13 & $\begin{array}{l}\text { Mais do que } 80 \% \text { do conselho de administração é composto } \\
\text { por conselheiros externos? }\end{array}$ \\
\hline & 14 & $\begin{array}{l}\text { O conselho de administração possui mandato unificado de um } \\
\text { ano? }\end{array}$ \\
\hline & 15 & A empresa não possui acordo de acionistas? \\
\hline \multirow[t]{5}{*}{ Estrutura de Propriedade e Controle } & 16 & A empresa emite apenas ações com direito a voto $(\mathrm{ON})$ ? \\
\hline & 17 & $\begin{array}{l}\text { As ações preferenciais correspondem a menos que } 50 \% \text { do } \\
\text { total de ações? }\end{array}$ \\
\hline & 18 & $\begin{array}{l}\mathrm{O}(\mathrm{s}) \text { controlador(es) possui }(\mathrm{em}) \text { menos do que } 70 \% \text { do total } \\
\text { de ações ordinárias? }\end{array}$ \\
\hline & 19 & $\begin{array}{l}\text { O excesso }(D I F) \text { de direitos de controle }(\% \mathrm{ON}) \text { em relação } \\
\text { aos direitos sobre o fluxo de caixa (\%TA) do controlador é } \\
\text { menor que } 23 \% \text { ? }\end{array}$ \\
\hline & 20 & $\begin{array}{l}\text { A empresa concede tag along aos detentores de ações prefe- } \\
\text { renciais? }\end{array}$ \\
\hline
\end{tabular}

nhias abertas brasileiras". Anais do $4^{\mathrm{O}}$ Encontro Brasileiro de Finanças, Rio de Janeiro, Julho, 2004 